\title{
Bringing global health home
}

\author{
Interview with Dr Bhooma Bhayana
}

Sissi Cao (Meds 2016), Han Yan (Meds 2017)

Faculty Reviewer: Dr Bhooma Bhayana, MD, FCFP (Department of Family Medicine)

Dr Bhayana is a family physician in London who also works with the London InterCommunity Health Center (LIHC) and the Newcomer Health Project, a Schulich initiative. She graduated from the Schulich School of Medicine and Dentistry in 1985, after which she worked in Toronto for 5 years. She is fluent in English, Hindi and Punjabi, and utilizes all 3 in her community work with recent immigrants and refugees. We met with Dr Bhayana over the phone to hear her thoughts on global health, to understand her involvement with multicultural initiatives and to gather advice for medical students interested in global health.

\section{UWOMJ: What does global health mean to you?}

Bhooma Bhayana: Global health is such a broad topic with so many academic definitions. To me, global health means that health is beyond what we do within the confines of our clinical encounters. Global health encompasses principles of environmental health, sustainability, equity and marginalization. When we talk of globalization, a familiar theme is that in the process of globalizing, we've ignored social justice and equity in health.

Tell us about your work in Toronto and how that sparked your interest in global health.

In Toronto, I worked with an innovative project called the Immigrant Women's Health Project based out of the Doctor's Hospital. We parked a mobile home in front of clothing factories and performed cancer screening for women working in the factories. It was that initiative that made me realize that "international" issues were the same issues present in our own backyard. From there, I decided to really focus on immigrant and refugee health. I came to London in 1989 and have been practicing here since, in a family practice as well as with the LIHC and now with the Newcomer Health Project.

\section{Tell us more about the Newcomer Health Project.}

From my work with the LIHC, I had seen a number of refugees and immigrants over the years arrive in London. When I started my own practice 1 really missed the work, so I spoke to the executive director of the Cross Cultural Learner's Center (CCLC) at the time. She had identified a real need: when refugees arrived, they could only use walk-in clinics for medical problems, which addressed immediate concerns but not chronic illnesses that needed follow-up care. We were inspired by Kevin Pottie, a physician in Ottawa and champion for refugee health, who had written in the Canadian Family Physician about a program in which medical students took the initial history at the clinic he worked at. It was a win-win situation: students would learn about cultural competency and the challenges faced by refugees, and refugees would have an opportunity to share their stories, give an in-depth history and begin to look after their health. We decided to duplicate that here and began a clinic on an ad-hoc basis. Now, we're at the point where we're working with pediatricians and internal medicine specialists to provide specialty clinics. It is an ever-evolving process.

\section{What are some challenges facing refugees in Canada today?}

There were some very large cuts that were announced to refugee health. Previously, all refugees were covered by the Interim Federal Health Program (IFHP) and government-assisted refugees were covered by IFH as well as the Ontario Health Insurance Plan (OHIP). The IFHP program covered limited dental and prescriptions, providing coverage similar to what someone on Ontario Works or welfare would receive. When cuts were announced, they removed both refugee claimants and privately-sponsored refugees from coverage. People would only be covered if their health concerns were a danger to public safety or public health (homicidal, infectious), but if they affected just their own health (suicidal), they weren't covered. This has created a huge gap for acute care: for example, there was a very high-profile case in Toronto where a refugee claimant from Latin America was faced with near-blindness from a retinal detachment. An ophthalmologist at St. Michael's Hospital ignored the new policy on a humanitarian basis and performed the surgery for free-the hospital had no choice but to absorb the costs of the surgery because they couldn't see somebody go blind for the lack of a simple procedure.

\section{Why do you think it's important for students to be aware of glob- al health issues?}

Western definitely has a really rich history of social justice within the medical school, and I would encourage students to become involved in its initiatives. When I was a medical student, I sought out those opportunities-for example, I was on the editorial staff of the University Of Western Ontario Medical Journal (UWOMJ) and discovered that writing was a good way to help encourage global health initiatives.

As a student, it is really important to know about global health issues in order to have awareness right at the beginning. We used to think health was purely biological, and then we began to think of it as being biological, psychological and social. We are now aware that it involves the entire ecosystem and that awareness is so important from the beginning because you begin to see the interconnectedness of things when you study disease processes. When I worked at the South Riverdale Community Health Center in Toronto, Dr Michael Rachlis, who was the New Democratic Party (NDP) health 
critic, noticed that a number of children within that community had disabilities. After the investigations revealed the cause to be environmental lead poisoning, he took a much more global approach and recognized that he needed to step out of the confines of the examining room and look at what was happening in the environment. He mobilized the community to stop Canada Metal from pumping lead into the environment and causing the poisoning. If we begin with that framework as a student, it really gives us the awareness needed to engage in health advocacy.

Have you had any international health-related experiences? Do physicians need to leave Canada to be involved in global health?

As a medical student, I went to India for 4 months and spent some time in New Delhi and some rural areas surrounding Delhi. I learned from that international elective the importance of marginalization-I spent a lot of time doing obstetrics and gynecology and recognized the gender inequity that was part of the developing world. That carries forward here: when immigrant women come to Canada, they end up having experienced that marginalization but also face the additional pressures that come with immigration.

I think we have so many opportunities to do work locally. Although a lot of my patients are refugees or new immigrants, it's always nice to seek out an additional project outside of practice that encompasses other interests. The Newcomer Health Project does that for me. One of my colleagues runs a clinic within the homeless shelter once a week, while another colleague is the physician representative to the school board and works on lunch programs in schools with children living in poverty. Engaging in one project outside of regular work is how my colleagues and I seek involvement in global health locally.

\section{What are some of the concerns of global health today? How have things changed?}

Sustainability and the environment are two huge challenges for global health in the future, and equity is an issue both internationally and at home. We also need to look at the bigger picture. Global health is a trans-discipline environment; a big challenge is learning to work with not just other health care disciplines but also with social scientists and policy makers.

Global health has changed a lot for the better. For one thing the world has become a much smaller place, so that sense of "us and them" doesn't exist now. The model has changed; we recognize now that we're all in this together, that we share a responsibility for the inequities of the world. There's instead a greater sense of "we're all in the same boat"-we're much more aware of the ethics of global health.

\section{Anything else you want to share?}

For students, engagement in global health can be daunting. What I would say is to do some soul-searching and find one project that speaks to your heart. Through the course of your work life, find one longitudinal project and keep it on the back burner of your dayto-day work life.
Dr Bhooma Bhayana received the 2013 College of Family Physicians of Canada (CFPC) Geeta Gupta Award for Equity and Diversity. The award recognizes the achievements of an outstanding family physician CFPC member (or a team) in active practice who has shown leadership and advanced awareness working in his or her practice and community to foster respect and understanding of a minority or underserviced population. 